\title{
Pós-operatório de homoimplante de costela avaliado por toracoscopia paraxifóide transdiafragmática modificada em gatos
}

\author{
Post-operative of toracoscopy paraxiphoid transdiaphragmatic modificed approach, in cats
}

\author{
Josaine Cristina da Silva Rappeti ${ }^{\mathrm{I}}$ Ney Luis Pippi ${ }^{\mathrm{II}}$ Fabrício de Vargas Arigony Braga ${ }^{\mathrm{I}}$ \\ Giancarlo Santini de Souza ${ }^{\text {III }}$ Giane D'Avila Coelho ${ }^{\text {IV }}$ Giane Magrini Pigatto $^{\text {IV }}$ Deisi Novosad $^{\text {III }}$

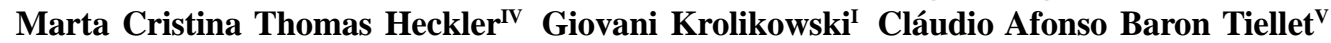

RESUMO

O objetivo deste estudo foi de avaliar a exeqüibilidade do acesso paraxifóide transdiafragmático modificado, em gatos, no período pós-operatório de homoimplante de costela para reconstituição de parede torácica. Para tanto foram avaliados 16 gatos após a reconstituição de parede torácica com o uso de homoimplante de costela conservado em açúcar. A cavidade torácica dos animais foi acessada por via transdiafragmática modificada, por meio de uma incisão de $2 \mathrm{~cm}$ na linha mediana paraxifóide para posterior introdução da cânula ao diafragma utilizando uma óptica de $10 \mathrm{~mm}$ de diâmetro. Foi identificado o terço médio da parede torácica, sendo necessário que os animais fossem posicionados em decúbito lateral obliquado. Foram constatadas aderências e visibilizado o aspecto dos implantes. Foi possível avaliar a parede torácica de gatos com óptica de $10 \mathrm{~mm}$ de diâmetro através do acesso transdiafragmático modificado.

Palavras-chave: toracoscopia, abordagem paraxifóide transdiafragmático, parede torácica.

\section{ABSTRACT}

The purpose of this study was to evaluate a modified thoracic access to test the rib homoimplant in cats. Sisteen adults cats was evaluated ofter thoracic wall reconstituition using a rib homoimplant preserved in sugar. The animals were submitted to a modified trans-diaphragmatic paraxiphoid access, using a optical of $10 \mathrm{~mm}$ diameter through the midline. The lateral oblique recumbency made become possible the identification of the medial third of the thorax, and it also allowed the identification the adhesions and the aspect of the implants. The evaluation thoracic cavity of the cats with an optic of $10 \mathrm{~mm}$ of diameter through the modified transdiaphragmatic paraxiphoid access.

Key words: thoracoscopy, paraxiphoid trans-diaphragmatic approach, rib.

\section{INTRODUÇÃO}

A cirurgia torácica vídeo-assistida ou toracoscopia é um exame auxiliar que, através de um endoscópio, propicia a visibilização da cavidade torácica e pode expor órgãos, neoplasias, aderências, metástases, abscessos e hérnias (De ZOPPA, 2003). De acordo com BECK (2003), para o procedimento de toracoscopia, são utilizados três pontos de punção torácica que poderão sofrer algumas alterações conforme a anatomia de cada cão. Ao realizar a ressecção pulmonar em eqüinos, De ZOPPA (2003) fez uma abordagem no $12^{\circ}$ espaço intercostal, outra no $14^{\circ}$ e no terceiro portal ventralmente ao primeiro. Segundo BECK (2003), o acesso toracoscópico tem como vantagem a melhor visibilização das alterações no interior da cavidade torácica.

Este tipo de exame tem sido utilizado para visibilização e ligadura do ducto torácico em cães

\footnotetext{
IPrograma de Pós-graduação em Medicina Veterinária (PPGMV), Universidade Federal de Santa Maria (UFSM), 97105-900, Santa Maria, RS, Brasil. E-mail: josainerappeti@yahoo.com.br. Autor para correspondência.

IDepartamento de Clínica de Pequenos Animais (DCPA), Centro de Ciências Rurais (CCR),UFSM, Santa Maria, RS.

IIICurso de Medicina Veterinária, DCPA, CCR, UFSM, Santa Maria.

${ }^{\mathrm{IV}}$ Médico Veterinário. Autônomo.

vNúcleo Setorial de Informática, CCR, UFSM, Santa Maria, RS.
} 
(MARYANN et al., 2002), pericardiectomia em cães (PETER et al., 1999), no diagnóstico e tratamento de hérnias diafragmáticas (BECK, 2003), nas toracoscopias exploratórias de cães e gatos com a finalidade de identificar a etiologia de efusão pleural, através da biópsia (KOVAK et al., 2002). Tem sido aplicada ainda em várias técnicas, como na correção do ducto arterioso patente em cães (RICHTER, 2006), na ventriculectomia parcial em cães (MARTINS, 2005) e na colopexia (BRUN, 2003). Da mesma forma, a videotoracoscopia foi considerada a abordagem ideal para biópsias cardíacas por MARTINS (2003). A abordagem paraxifóide transdiafragmática proporciona excelente visibilização das estruturas ventrais do tórax (POTTER \& HENDRICKSON, 1999). FOSSUM (2005), utilizando essa técnica após a remoção do mediastino, concluiu que esta permitiu exame cuidadoso de todo o tórax.

O objetivo deste estudo foi avaliar a parede costal de gatos através da visibilização do local implantado com homoimplante de costela por toracoscopia, utilizando uma ótica de $10 \mathrm{~mm}$ de diâmetro, com acesso paraxifóide transdiafragmático modificado.

\section{MATERIAL E MÉTODOS}

Foram avaliados 16 gatos após intervenções cirúrgicas de reconstituição experimental de três costelas em seu terço médio, sendo empregadas costelas homólogas conservadas em açúcar in natura (Ga) ou em solução a $300 \%$ (Gb). Os animais foram separados em dois grupos de oito, e todos os atos operatórios foram realizados no lado direito da parede torácica. O primeiro grupo foi avaliado após 60 dias de pós-operatório (quatro do Ga e quatro do Gb), e o outro foi submetido à avaliação aos 120 dias (quatro do Ga e quatro do Gb). Foi instilada heparina a $1 \%$ na cavidade torácica no momento em que foram implantadas as costelas, em oito gatos, sendo quatro do Ga e quatro do Gb, para evitar aderências.

Com uma óptica de 10mm de diâmetro (Ø), o local do implante foi observado e as imagens foram arquivadas em fitas VHS. Foi feita análise macroscópica do local, verificando-se também a presença ou não de aderências no pulmão. O equipamento utilizado para este procedimento foi o da marca Storz ${ }^{\circledR}$, composto por um monitor de vídeo de alta resolução, cânula de $10 \mathrm{~mm}$ $\varnothing\left(\right.$ Edlo $^{\circledR}$, RS) que serviu de conduto para a passagem do endoscópio rígido de $10 \mathrm{~mm}$ de $\varnothing$ e ângulo de visão de $0^{\circ}$, (Endoscópio Hopkins ${ }^{\circledR}$, Karl Storz $^{\circledR}$, RJ), acoplado a uma microcâmera (Telecam-DX ${ }^{\circledR}$ Karl Storz) e a um processador da microcâmera, a uma fonte de luz halógena (Fonte de luz 250 Karl Storz, RJ) e a um videocassete.
A óptica e a cânula foram colocadas em uma caixa plástica própria para imersão em uma solução de glutaraldeído a 2\%, durante 40 minutos. Após esta etapa, este material foi lavado com solução fisiológica e secado com compressas estéreis. Com o material sobre a mesa auxiliar, a microcâmera e o cabo de luz de fibra ótica foram revestidos por campos estéreis adaptados.

Com o animal em decúbito dorsal, em posição de Trendelemburg reverso e após todos os procedimentos de preparação para o ato cirúrgico asséptico, uma incisão pré-umbilical de $2,0 \mathrm{~cm}$ foi realizada na linha mediana. Ao expor os órgãos abdominais, e com o auxílio de uma pinça, o fígado foi afastado do diafragma, ampliando o campo de visão, para o acesso torácico.

O ligamento falciforme foi retirado e com uma pinça de Allis o músculo diafragma foi pinçado e tracionado levemente em direção ao abdome. Uma incisão de $1 \mathrm{~cm}$ foi realizada no mesmo, na posição de 11 horas. Através dessa incisão, foi introduzida uma cânula para a passagem da óptica e avaliação da parede torácica.

Para visibilização do local do implante, o animal foi reposicionado, ficando obliquado para o lado esquerdo na mesa e foi colocado um volume embaixo do tórax para elevá-lo. Para indicar o local do implante, o volante da equipe contou os espaços intercostais, fazendo movimentos nos músculo intercostais. A exploração da cavidade torácica foi feita registrando qualquer presença de calo ósseo, aspecto do implante e aderências no local.

Na seqüência, a óptica foi retirada e o fechamento do diafragma foi feito com um ponto em Wolff com fio de poliglactina 910, com diâmetro 4-0. No momento em que o nó foi apertado, foi realizada a insuflação pulmonar. A sutura na linha mediana foi feita com pontos de Sultan, com fio de poliglactina 910, calibre 4-0, e a redução do espaço morto em um padrão interrompido simples, com o mesmo tipo de fio. A pele foi suturada com pontos isolados simples com fio mononáilon 4-0.

\section{RESULTADOS E DISCUSSÃO}

O acesso transdiafragmático modificado através da incisão realizada na linha mediana para a toracoscopia paraxifóide facilitou as manobras cirúrgicas. Foi um acesso rápido, seguro e que possibilitou avaliar as estruturas de parede do tórax e dos órgãos, como citaram POTTER \& HENDRICKSON (1999) quando descreveram apenas uma incisão de pele entre o processo xifóide e as cartilagens caudocostais. $\mathrm{O}$ trocarter, segundo os autores, foi direcionado

Ciência Rural, v.37, n.5, set-out, 2007. 
cranialmente, lateral ao esterno, penetrando no diafragma.

A técnica utilizada no presente estudo permitiu o uso da óptica de $10 \mathrm{~mm}$, maior do que a usada rotineiramente nesta espécie, como relataram KOVAK et al. (2002), que empregaram uma óptica de $2,7 \mathrm{~mm}$ em gatos com infusão pleural, através de uma abordagem entre as costelas, próxima à junção costocondral. A vantagem da abordagem transdiafragmática é a possibilidade do uso da óptica de $10 \mathrm{~mm}$ para avaliar a parede costal de gatos, anteriormente sendo necessári uma óptica de $2,7 \mathrm{~mm}$, pois o acesso à cavidade torácica era através dos espaços intercoscais.

A opção por não usar o pneumotórax foi de acordo com FOSSUM (2005), a qual cita que a técnica paraxifóide difere da laparoscopia, pois as cânulas usadas devem ficar abertas para o meio externo, criando e mantendo assim um pneumotórax. Também MARTINS (2005), ao fazer biópsia no músculo cardíaco, não utilizou $\mathrm{CO}_{2}$, pois associou o equipamento de toracoscopia com o material convencional, obtendo sucesso no procedimento. Já BECK (2003), ao utilizar insuflação torácica, enfrentou alterações cardiorespiratórias, porém KOVAK et al. (2002) utilizaram uma agulha de Veress entre a quarta e a oitava costela para produzir pneumotórax e não relataram nenhuma alteração.

O ligamento falsiforme dificultou as manobras cirúrgicas, no momento da visibilização do diafragma, sendo necessária a remoção cirúrgica do mesmo em todos os animais do experimento. Este fato é comentado por BRUN (2003), o qual verificou que, nos casos de laparoscopia, uma das complicações é a punção deste ligamento, resultando em enfisema, quando utilizado o pneumoperitônio, e também por BECK (2003), ao afirmar que essa estrutura interfere negativamente durante o ato cirúrgico, pois reduz o campo de visão, sendo que o auxiliar deve manipular mais o endoscópio para garantir uma melhor visibilização do diafragma.

O redirecionamento do fígado com uma pinça facilitou ainda mais a abordagem ao diafragma, mesmo o animal estando em posição de Trendelemburg reverso. BRUN (2003) relatou que na posição de Trendelemburg, os órgãos comprimem o diafragma, dificultando a respiração, por isso foi utilizado Trendelemburg reverso onde os órgãos fazem o movimento para o diafragma pélvico melhorando a exposição ao diafragma torácico.

A incisão com o bisturi do diafragma tracionado, com o auxílio da pinça Allis, foi eficaz, pois não ocorreram lesões nos órgãos torácicos e facilitouse a visibilização do mesmo. BECK (2003) empregou uma tesoura de Metzembaum para provocar experimentalmente uma hérnia diafragmática em cães e POTTER \& HENDRICKSON (1999), para acessar o tórax, introduziram o trocarte e a cânula, bem como FOSSUM (2005), que colocou cânulas adicionais em um ou dois dos lados do tórax.

Os gatos foram reposicionados para melhor visibilizar a parede torácica do lado direito, facilitando a observação das estruturas. Além disso, o auxílio do volume abaixo do tórax melhorou a manipulação da óptica, pois o gato tem uma cavidade torácica pequena. KOVAK et al. (2002) referem-se ao procedimento toracoscópico como sendo eficiente para diagnósticos e procedimentos terapêuticos em cães e gatos, consistindo em uma opção que promove uma excelente visibilização das estruturas torácicas.

POTTER \& HENDRICKSON (1999) citaram que o acesso paraxifóide transdiafragmático permite uma boa avaliação do mediastino, dos pulmões e da parede ventral, porém a cirurgia experimental realizada neste estudo foi no terço médio da parede costal. A manobra de colocar o animal em decúbito lateral obliquado promoveu uma melhor avaliação do local cirúrgico e das aderências, mostrando que esse método diagnóstico, através de algumas modificações realizadas, foi conclusivo, como citam MARYANN et al. (2002), BECK (2003), De ZOPPA(2003) e RICHTER, (2006).

Nos gatos avaliados, foi identificado, no local onde foram retirados os músculos intercostais, que houve substituição por tecido fibroso (Figura 1). Naqueles animais em que foi possível avaliar o local implantado (10), observaram-se aderências (8) (Figura 1), união das interfaces receptor/implante (46 do total de 47 implantes), segmento do pulmão envolvendo o implante aos 60 dias de pós-operatório (2) (Figura 2) e atelectasia (1) do pulmão que envolveu o implante.

Ao serem avaliados aos 120 dias de evolução, três destes tiveram aderências no pulmão. Este resultado corresponde a um gato em que, após ter sido colocado o implante, ocorreu uma fratura de costela e um pino que migrou do canal medular (grupo com heparina). Do grupo que não recebeu heparina, apenas um, com 120 dias, apresentou essa complicação, que corresponde a um gato em que foi necessário refazer a cirurgia, pois as três agulhas saíram do canal medular, sendo realizada nova intervenção cirúrgica para colocar as agulhas de maior diâmetro. Dois animais foram do grupo a e os outros dois do grupo b.

Aos 60 dias, dois pulmões apresentaram aderências: um do grupo tratado com heparina e outro não. Os outros dois gatos com aderências foram do grupo com heparina, e não apresentaram nenhuma complicação no pós-operatório. 


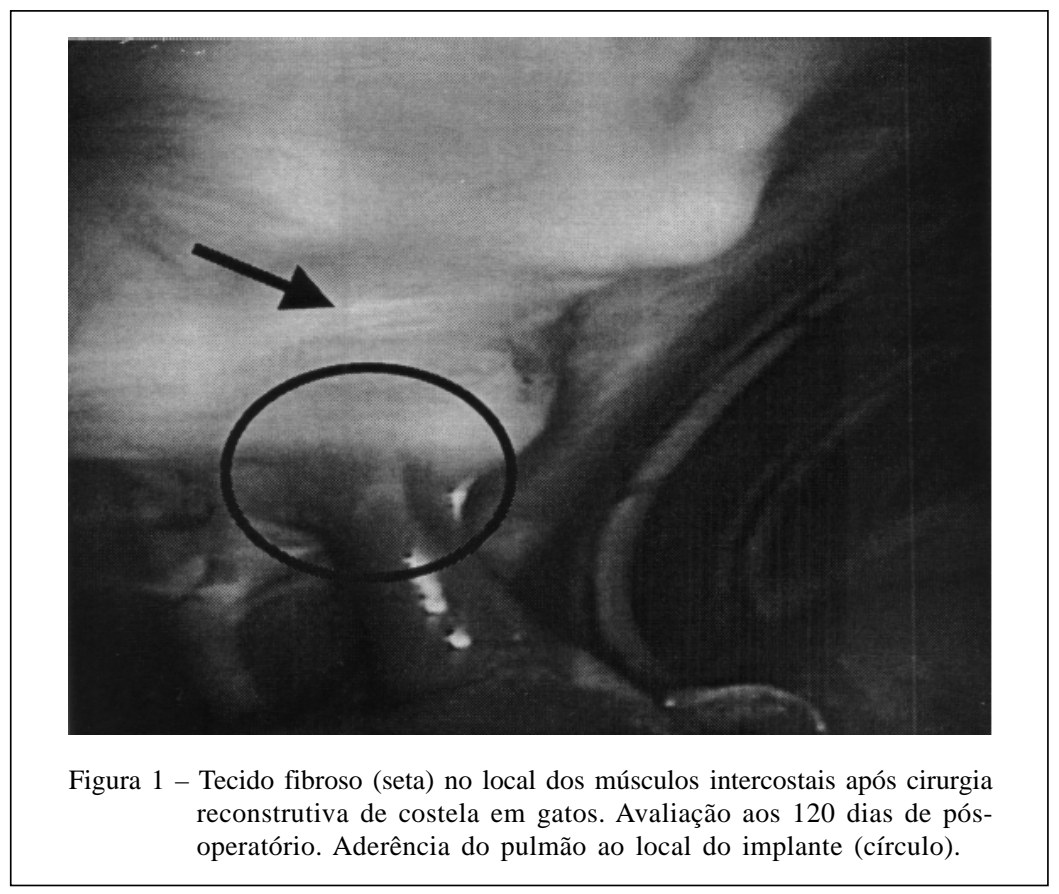

A presença de aderências do pulmão com a parede torácica dificultaram a avaliação do local da cirurgia em oito gatos, fato ressaltado também por BECK (2003), que encontrou, no seu estudo, um número elevado de aderências no interior do tórax, impedindo uma avaliação mais adequada. MARTINS (2005) utilizou heparina diluída em solução fisiológica a 1\%, e também encontrou aderências sobre o miocárdio, lobos pulmonares e destes com a parede costal. RAPPETI et al. (2003) igualmente constataram, nas avaliações macroscópicas, 10 gatos com aderência do pulmão ao implante. MARTINS (2005) comenta que o uso da heparina não evitou aderências, porém elas foram facilmente desfeitas. RICHTER (2006) encontrou aderências do lobo cranial pulmonar na parede costal quando fez a correção por cirurgia torácica vídeoassistida em 13 dos 14 cães que foram submetidos à indução experimental de ducto arterioso patente.

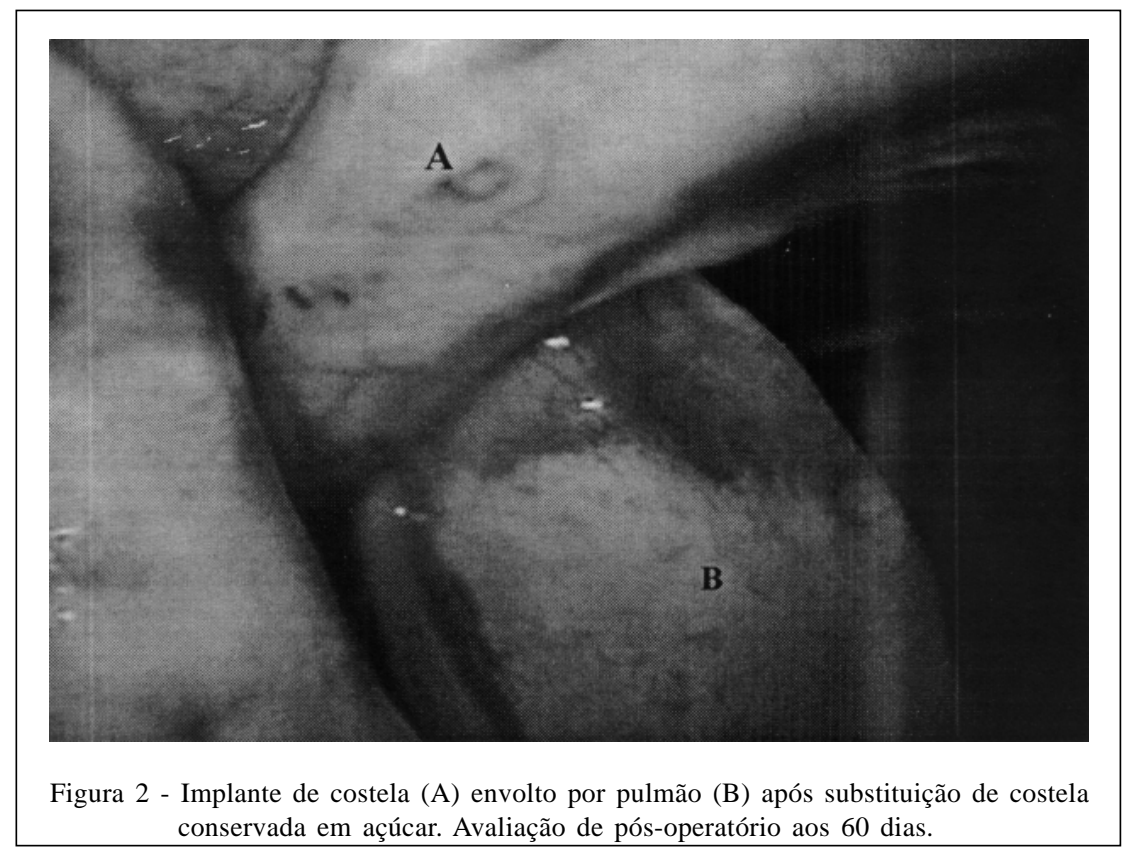

Ciência Rural, v.37, n.5, set-out, 2007. 
MAZZANTI (2000) também encontrou essa complicação na área de enxertia do diafragma com órgãos torácicos e abdominais.

Optou-se por não desfazer as aderências dos gatos utilizados neste experimento, pois MARTINS (2005), ao desfazê-las, observou hemorragia, sendo necessária a conversão a céu aberto, problema também enfrentado por RICHTER (2006). As aderências estão presentes nos procedimentos torácicos, usando-se ou não heparina, porém, com o seu uso, elas podem ser facilmente desfeitas (MARTINS, 2005). De acordo com estes resultados, no seu experimento, não houve nenhuma vantagem em utilizar a heparina.

A diferença entre os grupos de 60 e 120 dias foi que os implantes aos 60 dias apresentavam pouco tecido fibroso que os envolvia e estavam separados dos tecidos da parede torácica, embora já existisse o início de continuidade tecidual entre eles e a parede, como também apresentavam os calos ósseos bem evidentes e presença de neovascularização delimitadas. Aos 120 dias, mostraram um tecido fibrovascular envolvendo o local implantado e estavam interligados com a parede costal.

O fio escolhido para sutura no diafragma foi eficiente e, segundo BECK (2003), mostrou-se adequado tanto pela facilidade de manipulação quanto pela resistência na realização da sutura, concordando com MAZZANTI (2000), que comentou que, em seu experimento, o fio poliglactina 910 para o reparo do músculo diafragma suportou o gradiente de pressão exercido sobre ele.

Apenas um ponto de Wolff permitiu um bom vedamento da cavidade torácica, pois o orifício de acesso foi de $1 \mathrm{~cm}$, ao contrário de BECK (2003), que provocou um defeito maior, necessitando de sutura contínua. Nesse experimento, o uso do ponto em Wolff como ponto de eversão de bordas foi empregado devido a sua característica de ponto pneumático, como citou MAZZANTI (2000).

A restituição da pressão negativa por meio de insuflação pulmonar foi eficiente e de fácil emprego, sem necessitar da toracocentese utilizada por BECK (2003) e MARTINS (2005). FOSSUM (2005) comenta que, ao utilizar essa técnica após fechar o tórax, é necessário colocar uma sonda que deve ser removida no dia seguinte, porém, nesse estudo, não foi necessário fazê-lo.

\section{CONCLUSÃO}

O acesso paraxifóide transdiafragmático modificado permite avaliar com eficiência o terço médio da parede costal de gatos, com óptica de $10 \mathrm{~mm} \varnothing$, porém é necessário posicioná-los em decúbito lateral obliquado, com anteparo sob o tórax.

\section{COMITÊ DE ÉTICA}

Aprovado pelo Comitê de ética e bem-estar animal da Universidade Federal de Santa Maria: № 23081.008029/ 2006-86

\section{REFERÊNCIAS}

BECK, C.A. de C. Laparoscopia e toracoscopia nas hérnias diafragmáticas: um estudo experimental em cães. 2003. $217 f$. Tese (Doutorado em Medicina Veterinária) - Universidade Federal de Santa Maria.

BRUN, M.V. Colopexia por via laporascopica e convencional em cães. 2003. 183f. Tese (Doutorado em Medicina Veterinária) - Universidade Federal de Santa Maria.

De ZOPPA, A.L.V. Cirurgia torácica vídeo-assistida aplicada à ressecção pulmonar com o auxílio de sutura mecânica em eqüino. 2003. 123f. Tese (Doutorado em Medicina Veterinária) - Faculdade de Medicina Veterinária e Zootecnia da Universidade de São Paulo.

FOSSUM, T.W. Endoscopia de cavidades corporais. In: Cirurgia de pequenos animais. 2.ed. São Paulo: Roca, 2005. Cap. 6, p.127-132.

KOVAK, J.R et al. Use of toracoscopy to determine the ethiology of pleural effusion in dogs and cats: 18 cases (1998-2001). Journal of the American Veterinary Medical Association, v.221, n.7, p.990-994, 2002.

MARTINS, L.G.A. et al. Biópsia cardíaca por videotoracoscopia em cães. 2003. 15f. Seminário (Cirurgia Experimental) - Programa de Pós-graduação em Medicina Veterinária, Área de concentração Cirurgia Veterinária.

MARTINS, L.G.A. Ventriculestomia parcial em cães: controle pós-pperatório por videotoracoscopia. 2005. $75 f$ Tese (Doutorado em Medicina Veterinária) - Universidade Federal de Santa Maria.

MARYANN, G. et al. Thoracoscop visualization and ligation of the thoracic duct in dogs. Veterinary Surgery, v.31, p.138146, 2002

MAZZANTI, A. Músculo diafragma homólogo conservado em solução supersaturada de açúcar envolvido ou não com segmento omental para reparação do diafragma de cão. 2000. 62f. Dissertação (Mestrado em Medicina Veterinária) - Universidade Federal de Santa Maria.

PETER, J.W. et al. Thoracoscopic versus open partial pericardectomy in dogs: comparison of postoperative pain and morbidity. Veterinary Surgery, v.28, p.472-479, 1999.

POTTER, L.; HENDRICKSON, D.A. Therapeutic videoassisted thoracic surgery. In: FREEMAN, L.J. Veterinary endosurgery. St Louis: Mosby,1999. Cap.9, p.169-187.

RAPPETI, J.C.S. et al. Reconstituição experimental da parede torácica de gatos com implante heterólogo de cartilagem auricular conservada em glicerina a 98\%. Ciência Rural, v.33, n.6, p.1089-1094, 2003.

RICHTER. R.K. Ducto arterioso patente em cães: indução experimental por toracotomia, correção por cirurgia torácica vídeo-assistida (CTVA) e avaliação de aderências por toracoscopia. 2006. 83f. T ese (Doutorado em Medicina Veterinária) - Universidade Federal de Santa Maria, Santa Maria. 